record the results automatically. As a result of this saving of technicians' time it has been possible to deviate the technicians into performing more complex procedures where automation has not been possible.

We are aware that the capital cost of installing this equipment for this single purpose may deter some management committees. For our part we are satisfied that the money expended has been justified in the accuracy of the results obtained and the saving of technical time simultaneously achieved.

The fundamental basis of any automatic device is that it must be in constant use during the working day in order to get maximum value from it. Our work load is such that we are able to keep the Autoanalyser fairly fully occupied every day doing the haemoglobin determinations alone. In smaller laboratories which cannot employ the machine whole time for this purpose, it is possible, by using the remainder of the apparatus, to carry out other chemical estimations for which the machine is specifically designed.

Another criterion of successful automation of a laboratory procedure is that the machine must be easy to operate and be free from maintenance and service difficulties. We have found during the six-month period that this automated procedure has been in daily routine use that it has been trouble-free. The only routine replacements so far required have been the ink for the graphical recorder, Teflon tubing for the manifold, and servicing of the minimotor stirrer. The latter becomes noisy after constant use and brushes require replacement. Eventually, the small motor will wear out but this replacement is simple and cheap. We have found that a new motor is required after two to three months' constant use.

The main criticism of the replacement of a manual by an automatic method in a hospital laboratory is that training of the junior technicians is impaired. This might be true of some techniques but is not so valid when levelled at haemoglobinometry, because the hand method has still to be retained for the occasional venous sample on which the result may be required in an emergency, as well as for the determination of haemoglobin in "capillary' blood. As a result, the technician has still to perform the manual method but instead of carrying out a large number of haemoglobin estimations by hand he does only a percentage. This has, in our department, worked out at somewhat less than 2,000 haemoglobins per year. This number of tests is probably as many as a technician is likely to be called upon to do in a small laboratory. There seems little point in the endless repetition of a familiar method to the point of boredom and consequent possible inaccuracy.

In the development of this automated procedure, we should like to express our thanks first to our hospital committee for a generous grant towards 'automation' in our laboratory. This is but one of many uses to which this money has been put. The London agents of the Autoanalyser have been most helpful in setting up the method and solving the mixing problem on the sampler plate. All our technicians have contributed both interest and toil to the project which they now regard as amply rewarded.

\section{Improvement of the uric acid determination by the carbonate method for serum and urine}

F. EICHHORN, S. ZELMANOWSKI, E. LEW, A. $\overrightarrow{0}$ RUTENBERG, AND B. FANIAS From the Rappaport Laboratories, Biochemical Section, Beilinson Hospital, Petah Tikva, Israel

SYNOPSIS An improved colorimetric procedure for determining uric acid by the carbonate method in $\overrightarrow{0}$ serum and urine is described, using a $20 \%$ sodium carbonate solution with urea. Reliable results are 을 also obtained in high concentrations of uric acid.

The first method for determining uric acid colorimetrically was based on the reduction of phosphotungstic acid $\mathscr{C}$ by uric acid in the presence of concentrated sodium car- . bonate (Folin and Denis, 1912-13). Later the carbonate $\square$ was replaced by cyanide (Folin, 1930) to intensify the colour of the reaction mixture to be read visually. But the cyanide method has several drawbacks: a poisonous solution must be handled, the colour developed is not $\frac{\circ}{D}$ always reproducible, at concentrations of uric acid above $6 \mathrm{mg}$. \% the intensity of the developed colour is too weak $\overrightarrow{\overline{0}}$ and thus results are too low. When such high concentrations are encountered, the test must be repeated with $\supsetneq$ smaller amounts of serum or diluted Folin-Wu filtrate. We observed the loss of sensitivity in the cyanide method at high concentrations of uric acid while experimenting $\frac{?}{0}$ with uricase. With uricase even 12 to $14 \mathrm{mg}$. $\%$ of uric acid could be detected, while with cyanide this could not be done unless smaller amounts of serum were used.

We tried using strong alkaline coupled with weak 3 acid, such as sodium silicate, sodium borate, and sodium 0 glycerophosphates, as a possible replacement for cyanide. The best results, however, were not obtained with these $\frac{D}{O}$ reagents but with sodium carbonate, as in the original method (Folin and Denis, 1912-13). Carbonate was also $\mathrm{N}$ introduced anew by Caraway (1955). In his method the phosphotungstic acid reagent is used at a dilution of $\mathrm{N}$ $1: 10$ and ensures the final alkaline $p \mathrm{H}$ of 10 needed for $\mathrm{\omega}$ satisfactory development of colour. Under these condi- $\sigma$ tions, however, the sensitivity of the method is decreased. For higher concentrations of uric acid (above $5 \mathrm{mg} . \%$ ) this amount of reagent does not suffice and the standard $\Phi$ curve ceases to be linear. A larger amount of the acid reagent may be introduced and kept at $\mathrm{pH} 10$ and $20 \%$ of sodium carbonate instead of $10 \%$ is used. Under these $\frac{P}{D}$ conditions the colour is intensified. However, at this con- $\overparen{D}$ centration of carbonate a white precipitate appears and $\mathbb{D}$ makes the photometric determination impossible.

Received for publication 1 November 1960 . 


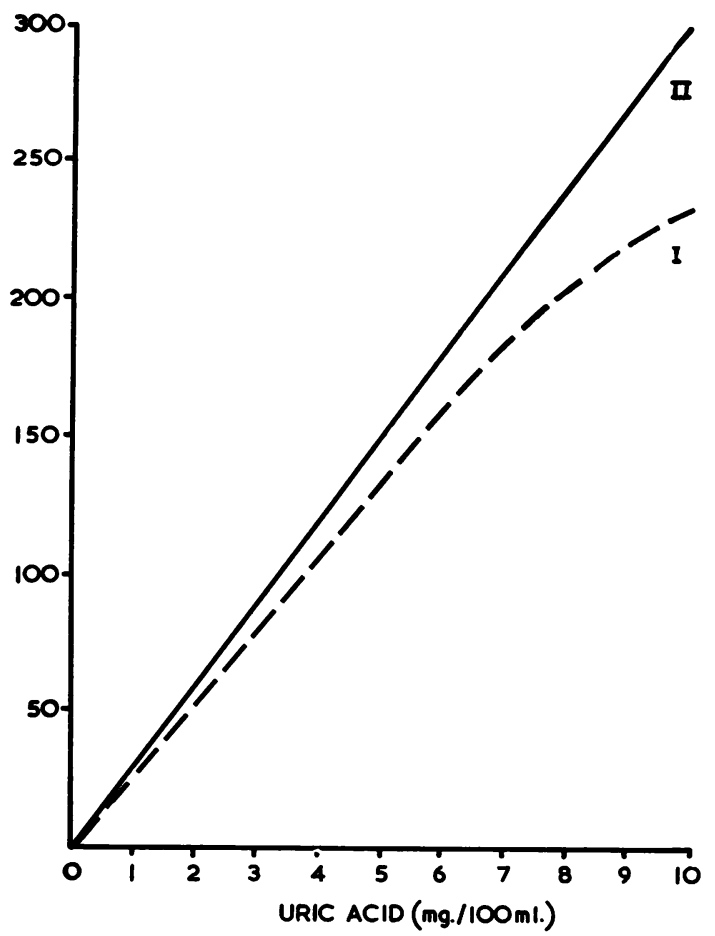

FIG. 1. Colorimetric readings on Klett-Summerson 640 $m \mu$ :

I With Caraway's reagents

II With the reagents of the present method

T A B LE

COLORIMETRIC READINGS

\begin{tabular}{ll} 
Uric Acid (mg.\%) & $\begin{array}{l}\text { With Caraway's } \\
\text { Reagent }\end{array}$ \\
\hline
\end{tabular}

\begin{tabular}{rrr}
\hline 1 & 28 & 30 \\
2 & 57 & 60 \\
3 & 86 & 90 \\
4 & 108 & 120 \\
5 & 135 & 150 \\
6 & 160 & 182 \\
7 & 182 & 210 \\
8 & 201 & 240 \\
9 & 214 & 272 \\
10 & 228 & 305
\end{tabular}

This difficulty has been surmounted by adding $15 \%$ urea to the sodium carbonate solution, as Brown (1945) did in the cyanide method. Thus the reagent may be added without precipitation while the $p \mathrm{H}$ stays at 10 and aids in the optimal development of colour.

In practice $0.1 \mathrm{ml}$. of the concentrated reagent produces the strongest colour with our urea-carbonate solution. The results are reliable and accurate in the highest concentrations of uric acid that occur in human blood.

\section{REAGENTS}

1 SODIUM TUNGSTATE Made up into a $2 \%$ solution in water.

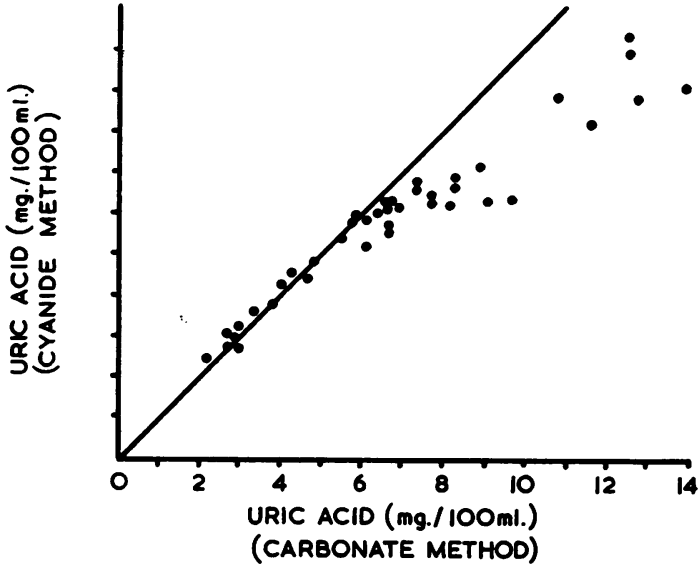

FIG. 2. Comparison of the results obtained by the carbonate and cyanide methods applied to the same filtrates.

\section{ONE SIXTH N SULPHURIC ACID}

3 SODIUM CARBONATE-UREA SOLUtION (a) $\mathrm{Na}_{2} \mathrm{CO}_{3}, 30 \mathrm{~g}$., is dissolved in water and made up to $100 \mathrm{ml}$. and (b) $45 \mathrm{~g}$. urea dissolved in water and made up to $100 \mathrm{ml}$. Two parts of $(a)$ are mixed with one part of $(b)$, resulting in a $20 \% \mathrm{Na}_{2} \mathrm{CO}_{3}$ to $15 \%$ urea solution. This mixture keeps well for two weeks.

4 PHOSPHOtUNGSTIC ACID REAGENT (FOLIN AND DENIS) One hundred grams of molybdate-free sodium tungstate $\left(\mathrm{Na}_{2} \mathrm{WO}_{4} \cdot 2 \mathrm{H}_{2} \mathrm{O}\right)$ are dissolved in $100 \mathrm{ml}$. of water, $80 \mathrm{ml}$. of $85 \%$ phosphoric acid is added, and the mixture is boiled gently with the aid of a reflux condenser for two hours. It is then cooled and diluted with water to one litre.

5 URIC ACID STANDARD For the stock standard (100 mg. per $100 \mathrm{ml}$.), $1 \mathrm{~g}$. of pure uric acid and $0.6 \mathrm{~g}$. of lithium carbonate are dissolved in about $150 \mathrm{ml}$. of water (warm if necessary). When completely dissolved $20 \mathrm{ml}$. of formalin $40 \%$ and $500 \mathrm{ml}$. of water are added. Finally, $25 \mathrm{ml}$. of $1 / \mathrm{N}$ sulphuric acid is added and made up with water to 1 litre.

WORKING STANDARDS Aliquots of the stock solution are diluted with water to provide standard solutions from 0.1 to $1 \mathrm{mg} . \%$. For the standard curve $2 \mathrm{ml}$. of these solutions is treated exactly like the serum centrifugates and corresponds to 1 to $10 \mathrm{mg}$. \% of uric acid respectively.

\section{PROCEDURE FOR SERUM}

Add to $0.3 \mathrm{ml}$. of serum $1.5 \mathrm{ml}$. of $2 \%$ sodium tungstate (1) and follow by $1.2 \mathrm{ml}$. of $1 / 6 \mathrm{~N} \mathrm{H}_{2} \mathrm{SO}_{4}$ (2). Mix and centrifuge for 10 minutes. To $2 \mathrm{ml}$. of clear supernatant add $0.4 \mathrm{ml}$. of the carbonate-urea solution (3) and follow immediately by $0.1 \mathrm{ml}$. of the phosphotungstic acid reagent (4). For the blank, treat $2 \mathrm{ml}$. of water, and for the standard, each $2 \mathrm{ml}$. of the working standard solutions 


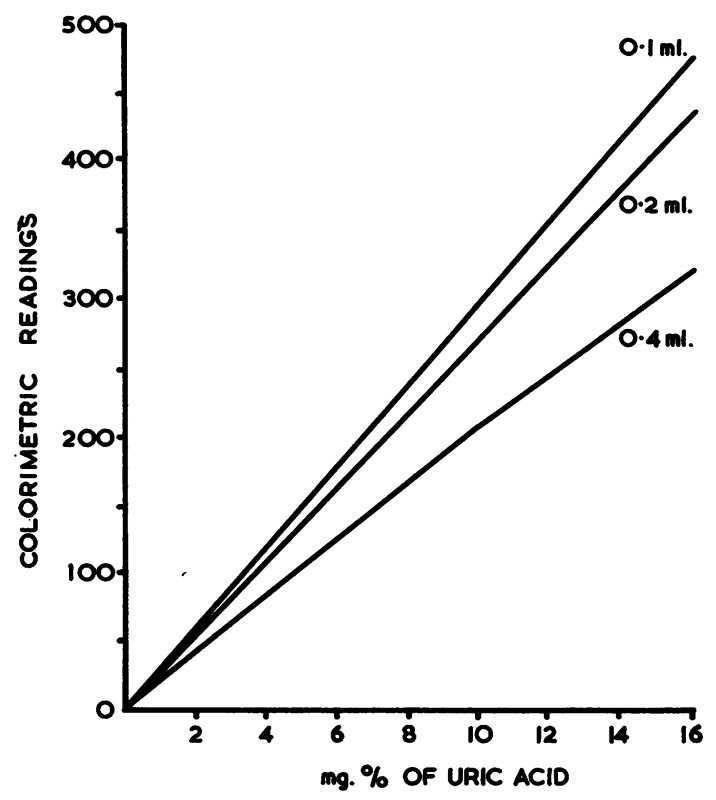

FIG. 3. Standard curves with different amounts of phosphotungstic reagent calculated by the present method.

(5) (corresponding to 5 and $10 \mathrm{mg}$. $\%$ uric acid) exactly as in the serum filtrate. Read after 10 minutes at $640 \mathrm{m \mu}$ in a photocolorimeter. We use a Klett-Summerson colorimeter coupled to a Kipp galvanometer (Rappaport and Eichhorn, 1955). Read the standard first as its colour slightly intensifies on standing. The samples should be read within the next 10 minutes.

The calculation is as follows:-

Concentration of standard $\times$ reading of test sample (unknown)

Reading of standard

\section{PROCEDURE FOR URINE}

Add to $0.2 \mathrm{ml}$. of urine $12.3 \mathrm{ml}$. distilled water; follow with $0.5 \mathrm{ml}$. phosphotungstic reagent (4) and then with $2 \mathrm{ml}$. of the carbonate solution (3). For the blank, treat $0.2 \mathrm{ml}$. of water and for the standard $0.2 \mathrm{ml}$. of the halfconcentrated standard (5) (corresponding to $50 \mathrm{mg}$. \% uric acid) exactly as in the procedure for serum. Read and calculate in the same way as for serum.

Preliminary experiments in the development of this method were performed during the life time of the late Professor F. Rappaport, whose original guidance we gratefully acknowledge.

\section{REFERENCES}

Brown, H. (1945). J. biol. Chem., 158, 601.

Caraway, W. T. (1955). Amer. J. clin. Path., 25, 840.

Folin, O. (1930). J. biol. Chem., 86, 179.

-, and Denis, W. (1912-13). Ibid, 13, 469.

Rappaport, F., and Eichhorn .F. (1955). Lab. Dig., 19, no. 5, p. 8.

\section{Book reviews}

MACKIE AND MCCARTNEY'S HANDBOOK OF BACTERIOLOGY.

Edited by Robert Cruickshank. (Pp. xi +980 . 40s.)

Edinburgh and London: E. \& S. Livingstone. 1960.

'Mackie and McCartney' has enjoyed a well-deserved $\vec{\circ}$ popularity for the past 35 years. There can be few departments of bacteriology where this handbook cannot be $\vec{\omega}$ found on the shelves in a well-thumbed condition and it has played an important part in raising British medical bacteriology to the high esteem in which it is justly held $\vec{A}$ throughout the world. To bring out a new and radically revised edition of such a work is no easy task, but one which Professor Cruickshank and his colleagues have $f$ achieved with brilliance. In spite of the use of smaller 0 print in many places there are 303 more pages than in the 9th edition-an indication of the amount of new material included.

The intensely practical spirit of the book remains unchanged and the selection and description of the $\overrightarrow{\mathscr{C}}$ practical methods is excellent. This, combined with an up-to-date outlook and an almost equal competence in $\square$ all branches, renders the volume without a peer in the technical bacteriological literature. In fact it is difficult to criticize it even in minor respects. In the brief section $\bar{\partial}$ dealing with virulence the author could have emphasized

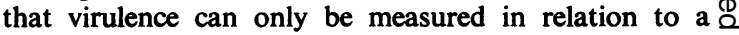
species, and that such findings may be difficult to translate $\vec{F}$ into terms of human disease. This concept is of particular importance in relation to mycobacteria.

On the purely technical side mention could have been $\frac{?}{0}$ made of the platinum tube dropping pipettes, as these are more accurate and more convenient than the all-glass? ones. It is a pity that the semantic difficulty in the term 'Treponema complement fixation test' is continued. The 3 Portnoy-type antigen obtained from Treponema pallidum is mentioned together with the antigen obtained from the non-virulent Reiter treponema, although Pillot and Borel have shown that at least one antigen specific to the $\mathrm{O}$ Nichols strain exists. The section dealing with antibiotic $D$ interactions correctly defines synergism and antagonism as a greater or lesser bactericidal effect than equivalent $\bar{N}$ concentrations of individual components alone, but un- $\sigma$ fortunately gives the method of Lamanna and Shapiro $N$ which reveals interaction at the bacteriostatic level only. $N$ However, Chabbert's method, which is the method of choice for antibiotic interactions, is also fully given. The chapters devoted to viruses, fungi, and protozoa are을 necessarily short. It is doubtful whether the inclusion of $\bar{\varnothing}$ virus diseases in a text primarily devoted to bacteria can $\stackrel{\mathscr{S}}{?}$ do justice to this vast and important subject. Within the $T$ necessary limitations of space, however, Dr. Swain has $O$ given a lucid and excellent summary of the more impor-零 tant human virus diseases.

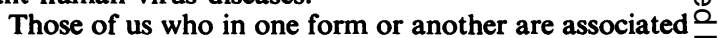
with the provision of a bacteriological service in the diagnostic or preventive fields are immensely grateful to 